Check for updates

Cite this: RSC Adv., 2017, 7, 45211

Received 27th July 2017

Accepted 15th September 2017

DOI: $10.1039 / \mathrm{c} 7 \mathrm{ra0} 0312 \mathrm{~b}$

rsc.li/rsc-advances

\title{
Nitroimidazolic radiosensitizers investigated by electrospray ionization time-of-flight mass spectrometry and density functional theory $\dagger$
}

\author{
S. Pandeti, ${ }^{\text {abc }}$ L. Feketeová, (D) *ade T. J. Reddy, ${ }^{c}$ H. Abdoul-Carime, ${ }^{a}$ B. Farizon, ${ }^{a}$ \\ M. Farizon ${ }^{a}$ and T. D. Märk ${ }^{d}$
}

\begin{abstract}
Radiosensitizers are important compounds used in radiotherapy to enhance tumor control of radioresistant hypoxic tumors. Despite their use in biological applications, little is known about the fundamental properties of these compounds. Nevertheless, understanding the ionization reactions of these compounds is crucial in evaluating the potential of radiosensitizers and in developing new and more effective drugs. The present study investigates the positive and negative electrospray ionization and subsequent low-energy collisioninduced dissociation reactions of ions derived from 1-methyl-5-nitroimidazole, metronidazole, ronidazole, ornidazole and nimorazole using a hybrid quadrupole time of flight mass spectrometer equipped with an electrospray ionization source (ESI-Q-TOF). Quantum chemical calculations are performed to obtain in addition the proton affinities, deprotonation energies, and electron affinities of the investigated compounds.
\end{abstract}

\section{Introduction}

Nowadays, cancer has become one of the leading causes of death worldwide and has been seriously endangering the health and life of humans for an extended period of time. ${ }^{1}$ Treatment is often based on a strategy which commonly combines surgery, chemotherapy and radiotherapy. Half of the patients are treated by radiation therapy, and show a wide variability in tumor response to the radiation from patient to patient. ${ }^{2}$ In radiation therapy the absorption of a high energy particle can lead to serious biological consequences, for example, damage to DNA can take place either through the direct effect of ionization or indirectly through the formation of $\mathrm{H}^{\cdot},{ }^{\circ} \mathrm{OH}$ and carbon radicals $^{3,4}$ and secondary electrons. ${ }^{5}$ The radicals can attack the nucleobases or the sugar backbone leading to DNA strand breaks. Moreover oxygen present can react with free radicals and modify the response of irradiated cells. If oxygen is not

\footnotetext{
${ }^{a}$ Université de Lyon, Université Claude Bernard Lyon1, Institut de Physique Nucléaire de Lyon, CNRS/IN2P3, UMR 5822, 69622 Villeurbanne Cedex, France. E-mail: l. feketeova@ipnl.in2p3.fr; Tel: +33-472431259

${ }^{b}$ Medicinal and Process Chemistry Division, CSIR-Central Drug Research Institute, Lucknow-226 031, India

'Analytical Chemistry and Mass Spectrometry Division, CSIR-Indian Institute of Chemical Technology, Hyderabad-500 007, India

${ }^{d}$ Institut für Ionenphysik und Angewandte Physik, Leopold Franzens Universität Innsbruck, Technikerstrasse 25, 6020 Innsbruck, Austria

${ }^{e}$ Center for Molecular Biosciences Innsbruck (CMBI), Leopold Franzens Universität Innsbruck, Technikerstrasse 25, 6020 Innsbruck, Austria

$\dagger$ Electronic supplementary information (ESI) available. See DOI: $10.1039 / \mathrm{c} 7 \mathrm{ra} 08312 \mathrm{~b}$
}

present, as in the case of hypoxic tumor cells, the same dose of radiation has been shown to be considerably less effective. ${ }^{6}$ In addition solvated electrons can react via molecular electron attachment, either forming a stable negatively charged species or leading to fragmentation via electron attachment dissociation. For instance, it has been observed that the DNA single and double strand breakage can be induced by solvated electrons. ${ }^{7}$

Radiosensitizers are a class of compounds that are capable if present to differentially sensitize hypoxic cells thereby enhancing the lethal effects of ionizing radiation. ${ }^{8,9}$ At present the potential of radiation used in radiotherapy is not fully exploited, due to the lack of understanding of the chemical and physical processes at the molecular level. Radiosensitizers used in the treatment of hypoxic cells are called 'electron-affinic' since studies in bacteria, bacterial spores, and cell cultures have shown a relationship between the efficiency of sensitization and the electron affinity of the compound. ${ }^{\mathbf{1 0}}$ However, the detailed mechanism by which the radiosensitization operates is still unknown, and thus, it is difficult to make a progress in the design of more efficient and less toxic substances for treatment.

Nitroimidazolic radiosensitizers accumulate in hypoxic cancer cells due to the radical induced chemistry taking place in the oxygen deficient environment ${ }^{11}$ and the formation of a radical anion is believed to be the first key step in this process. However, as mentioned above, (i) secondary electrons created upon radiation impact also substantially contribute to the induction of radiation damage through formation of a variety of ions and (ii) their production and unimolecular decomposition paths are unknown for most of the radiosensitizers, that is also for nitroimidazolic radiosensitizers considered in the present study. 
Thus, the present paper aims to provide new information in this matter by focusing on (i) the formation of positive and negative ions of 1-methyl-5-nitroimidazole (1Me5NI), metronidazole (METRO), ronidazole (RONI), ornidazole (ORNI) and nimorazole (NIMO) (Fig. 1) produced by electrospray ionization (ESI), and (ii) their fragmentation in low-energy collisioninduced dissociation (CID), i.e., in multiple collisions with an $\mathrm{Ar}$ gas. Our selection of the 5-nitroimidazolic compounds includes $1 \mathrm{Me} 5 \mathrm{NI}$ as a model compound, NIMO that has a clinical use in radiotherapy (see below) and changes molecular structure from 1Me5NI only at N1 position (see Fig. 1), and METRO, ORNI and RONI that have already established medicinal use and modify molecular structure of $1 \mathrm{Me} 5 \mathrm{NI}$ at $\mathrm{N} 1$ and $\mathrm{C} 2$ positions. Importantly, ESI in the negative mode has led to the formation of radical anions of many of the investigated radiosensitizers. It is well known that ESI transfers analyte ions from solution to the gas phase, and the types of ions that are commonly observed are pseudo molecular even-electron ions, such as protonated/deprotonated $\left([\mathrm{M}+n \mathrm{H}]^{n+},[\mathrm{M}-n \mathrm{H}]^{n-}\right)$ or cationized analytes, such as, $[\mathrm{M}+\mathrm{Na}]^{+}$ions. In contrast, molecular radical ions are observed rarely. Formation of radical cations under positive ion ESI, $\mathrm{M}^{+}$, occurs for easily oxidizable compounds, ${ }^{12-16}$ and this is promoted by high ESI voltage, high analyte concentration and selection of solvent(s) that stabilize the radical cation. Formation of radical anions, $\mathbf{M}^{{ }^{-}}$, in the negative ion mode of ESI was observed for molecules with high electron affinity, ${ }^{17-21}$ including NIMO and misonidazole both of which were investigated in a recent study. ${ }^{22}$ Thus, we have studied the formation of $\mathrm{M}^{--}$and $[\mathrm{M}-\mathrm{H}]^{-}$of the compounds shown in Fig. 1, and this experimental study was complemented by quantum chemical calculations. With the use of the density functional theory (DFT) we have evaluated basic properties of all compounds investigated here, such as, proton affinity (PA), electron affinity (EA), and deprotonation reactions.

Only a few analytical and bioanalytical studies have been reported in the literature on the compounds shown in Fig. 1. NIMO has been tested in the clinic and is in clinical use in radiotherapy in Denmark (following the DAHANCA 5 clinical trial) ${ }^{23}$ to enhance tumor control of radioresistant hypoxic tumors in head and neck cancer. A recent review by Overgaard summarizes the clinical use of nitroimidazolic radiosensitizers for over 10000 patients treated for head and neck carcinoma. ${ }^{24}$ The detection of RONI in muscle tissue was investigated using liquid chromatography (LC) MS..$^{25}$ Characterization of ORNI metabolites in human bile by ultra performance LC/quadrupole time-of-flight mass spectrometry was reported and proposed ORNI biotransformation pathways were given. ${ }^{26}$ Recently, Feketeová et al., explained the formation of radical anions of NIMO and related model compounds via electrospray ionization. ${ }^{22}$ Obviously, there is a lack of knowledge on the basic properties and fragmentation reactions of nitroimidazolic radiosensitizers.

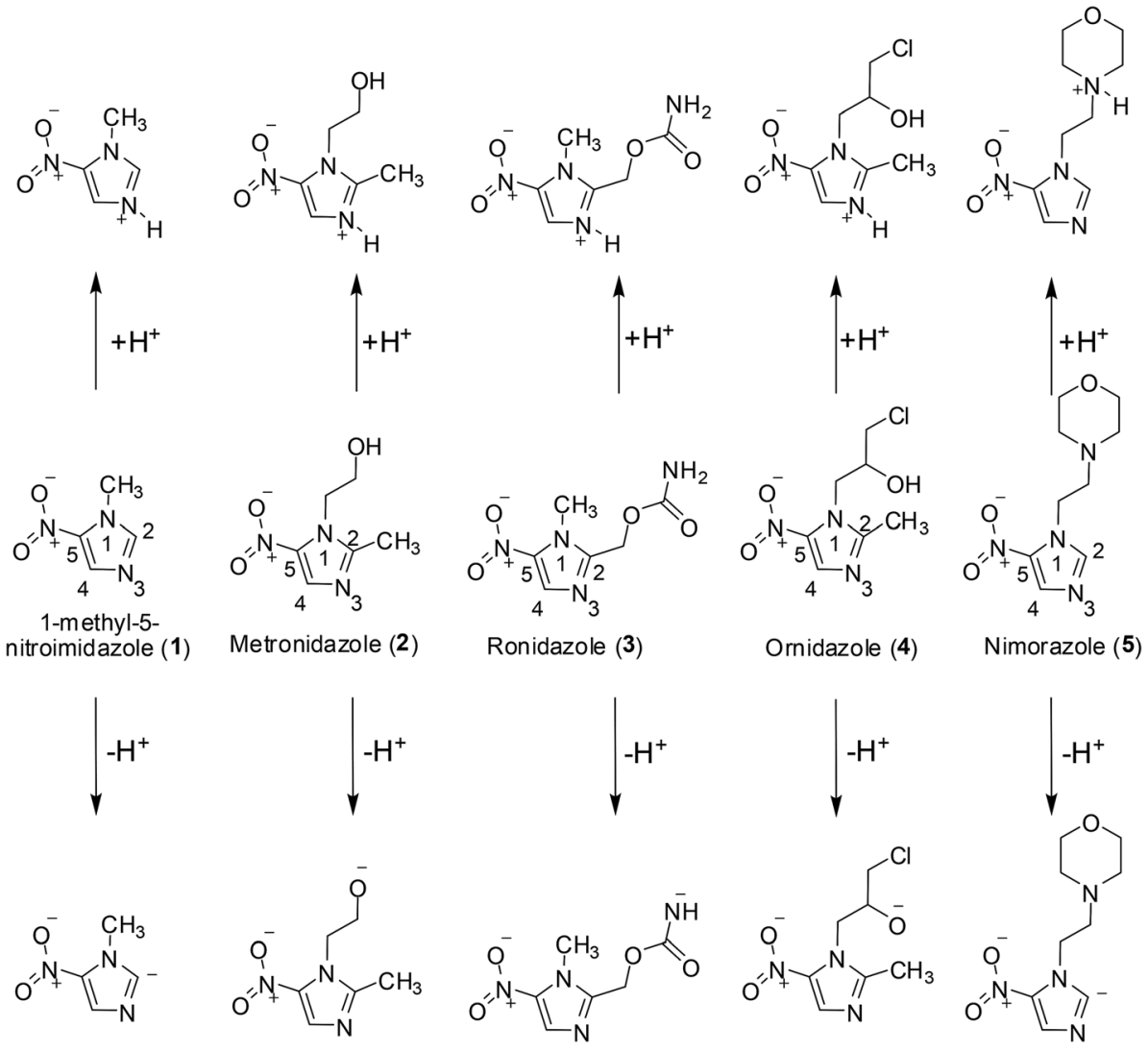

Fig. 1 Molecular structures of the five radiosensitizers investigated here: $1 \mathrm{Me} 5 \mathrm{NI}, \mathrm{METRO}, \mathrm{RONI}$, ORNI, and NIMO and the structure of their corresponding N3-protonation $[\mathrm{M}+\mathrm{H}]^{+}$and deprotonation $[\mathrm{M}-\mathrm{H}]^{-}$products. 


\section{Results and discussion}

The studied compounds 1ME5NI, METRO, RONI, ORNI and NIMO are all 5-nitroimidazoles, that have a $\mathrm{NO}_{2}$ group attached to the $\mathrm{C} 5$ position of the imidazole ring. They differ in their substitutions at the first (N1) and second (C2) positions of the imidazole ring (see Fig. 1). 1ME5NI and NIMO only differ at the first position to which is attached a methyl and ethyl morpholine moieties, respectively. The structural difference between METRO and ORNI is also at the first position, to which is attached either ethanol or a 3-chloro-2-hydroxy propyl group, respectively. In the case of RONI, a methyl carbamate group is attached at the second position while a methyl group is attached at the first position of the imidazole ring (Fig. 1). The lowest energy structures optimized at the M062x/6-311+G(d,p) level of theory and basis set are summarized for all the compounds in the (ESI), Fig. S1-S5. $\dagger$

Table 1 M062x/6-311+G(d,p) calculated dipole moments $\mu$ and quadrupole moments $\Theta$

\begin{tabular}{lll}
\hline Compound & $\begin{array}{l}\text { Dipole moment } \\
\mu \text { (Debye) }\end{array}$ & $\begin{array}{l}\text { Quadrupole moment } \\
\Theta \text { (Debye-Ang) }\end{array}$ \\
\hline 1-Methyl-5-nitroimidazole & 4.4 & 2.5 \\
Metronidazole & 4.7 & 6.7 \\
Ronidazole & 5.2 & 10.1 \\
Ornidazole & 4.2 & 10.2 \\
Nimorazole & 4.8 & 3.6
\end{tabular}

The high values of M062x/6-311+G(d,p) calculated dipole and quadrupole moments of all the compounds, $\mu$ and $\Theta$ (see Table 1), respectively, suggest that these compounds should all be able to form radical anions, such as, dipole bound anions, ${ }^{27}$ or to initiate some specific dissociation processes, e.g., Vibrational Feshbach Resonances. ${ }^{28}$ However, this would become especially relevant in gas-phase electron-attachment experiments.

\section{Formation of the protonated $[\mathrm{M}+\mathbf{H}]^{+}$ion}

The structures of each possible protonated $[\mathrm{M}+\mathrm{H}]^{+}$ion of 1Me5NI, METRO, RONI, ORNI, and NIMO were investigated by M062x/6-311+G(d,p) level of theory and the calculated values are shown in Fig. 2. The highest PA for all investigated radiosensitizers is on the $\mathrm{N} 3$ of the imidazole ring ( $9.06 \mathrm{eV}$ to $9.48 \mathrm{eV}$ ) as opposed to protonation on the oxygen of the $-\mathrm{NO}_{2}$ group for which the calculated values are found to be about $1 \mathrm{eV}$ lower in general (Fig. 2). However, for NIMO, the highest value for the PA is found at the nitrogen site of the morpholine ring $(9.54 \mathrm{eV})$, while the proton affinity of the nitroimidazole ring is nearly as low as for $1 \mathrm{Me} 5 \mathrm{NI}$. The calculated PAs are in the relative order of 1 Me5NI < RONI < ORNI < METRO < NIMO.

An examination of the positive ion ESI mass spectra of all five radiosensitizers, $1 \mathrm{Me} 5 \mathrm{NI}$, METRO, RONI, ORNI and NIMO, Fig. 3a-e, respectively, immediately reveals that the most abundant ion in each case is the $[\mathrm{M}+\mathrm{H}]^{+}$ion. The intensity of all other ions is normalized to the most abundant ion, i.e., $[\mathrm{M}+$ $\mathrm{H}]^{+}$. We also observe a protonated dimer $\left[\mathrm{M}_{2}+\mathrm{H}\right]^{+}$ion for METRO (Fig. 3b) and RONI (Fig. 3c), in case of RONI a sodiated

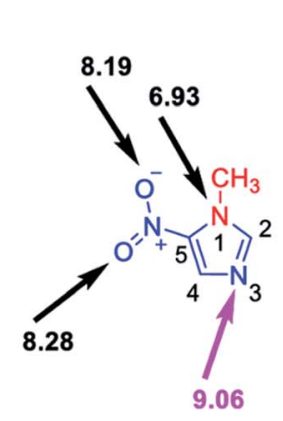

1-methyl-5-nitroimidazole (1)

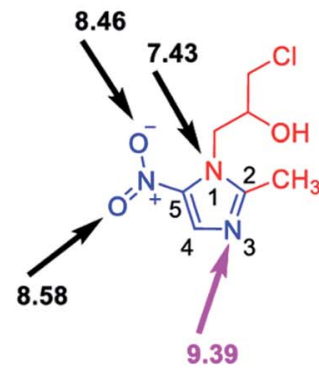

Ornidazole (4)

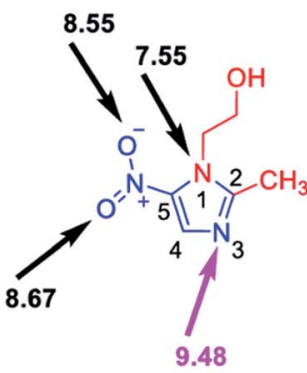

Metronidazole (2)

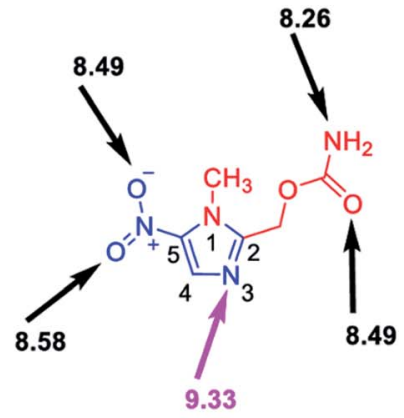

Ronidazole (3)

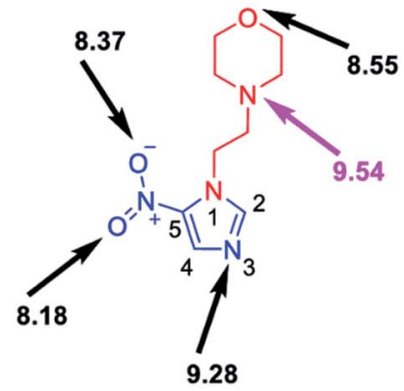

Nimorazole (5)

Fig. $2 \mathrm{M062x} / 6-311+G(\mathrm{~d}, \mathrm{p})$ calculated proton affinities $(\mathrm{eV})$ for each possible protonation site (ground state $0 \mathrm{~K}$ ). Note, that the optimization of (3) and (5) protonated at N1 position converged to the protonation at N3, and at N of the morpholine ring, respectively. In addition, optimization of the protonation of the second oxygen in the side group in (3) resulted in the protonation at N3. 
(a)

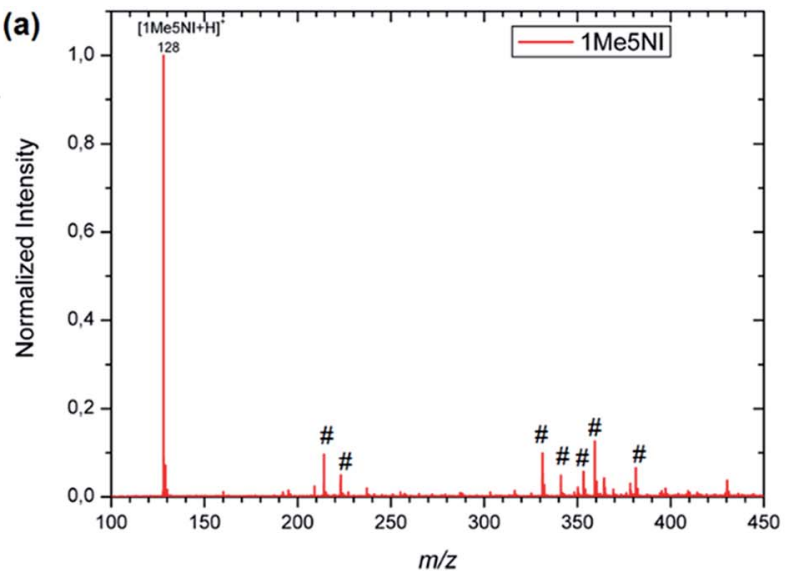

(b)

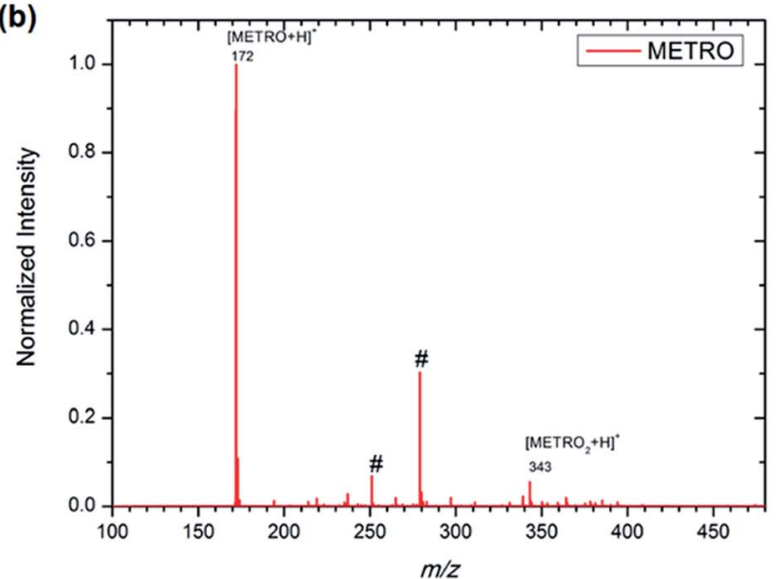

(c)

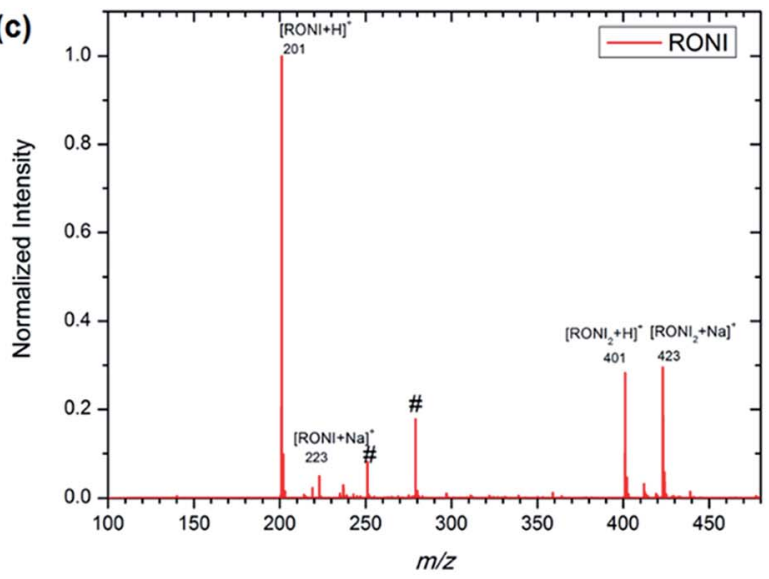

(d)

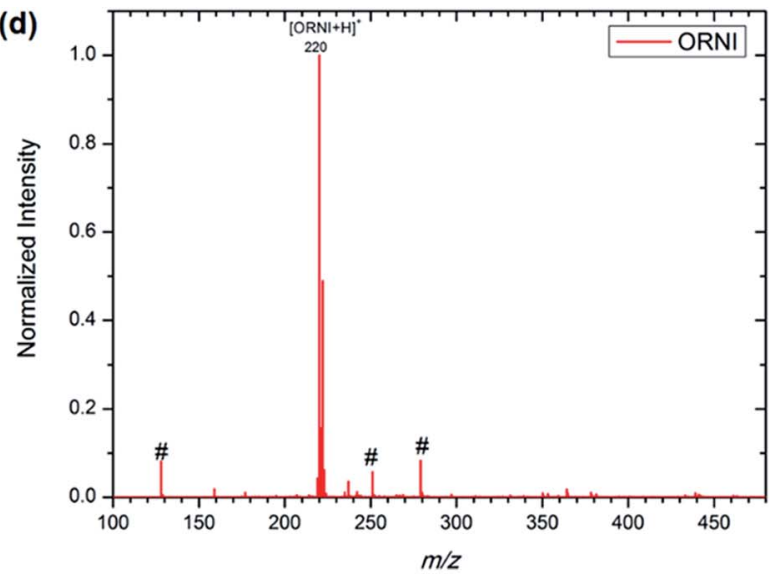

(e)
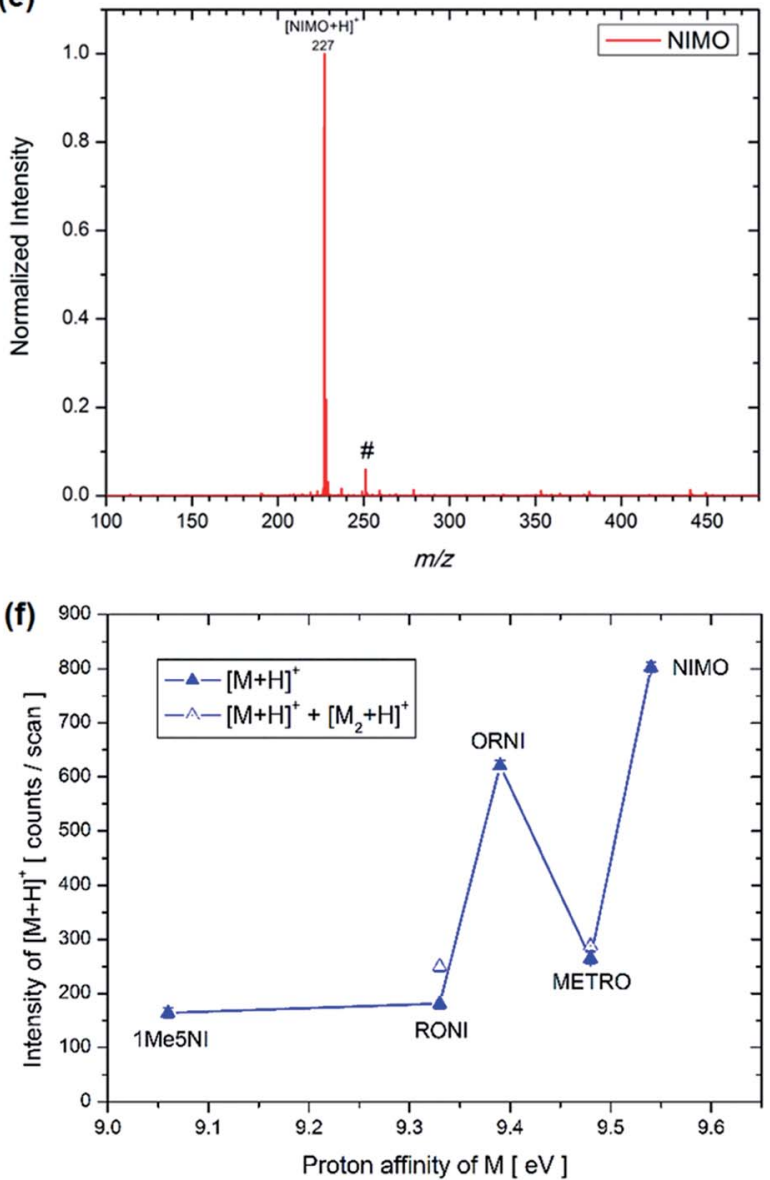

Fig. 3 Positive electrospray ionization mass spectra of a solution of $5 \mathrm{mM}$ of (a) 1 Me5NI (b) METRO (c) RONI (d) ORNI (e) NIMO in methanol/ water/acetic acid (50/50/1); (f) ion intensity of $[\mathrm{M}+\mathrm{H}]^{+}$in counts per scan plotted as a function of PA of $\mathrm{M}$. Background peaks are designated by \#.

dimer ion $\left[\mathrm{RONI}_{2}+\mathrm{Na}\right]^{+}$can also be observed. The sodiated analytes are commonly observed in ESI due to the sodium originating from laboratory glassware or solvents. Due to the fact that same solvents and clean glassware were used for all the compounds here, we note an increased affinity of RONI towards sodium cation shown by relatively abundant monomer [RONI + $\mathrm{Na}]^{+}$and highly abundant dimer $\left[\mathrm{RONI}_{2}+\mathrm{Na}\right]^{+}$. This is likely due to the presence of a polar amide group in RONI, which is known to form strong bonds with metal ions, in comparison to other investigated radiosensitizers in this study (see Fig. 2). METRO and RONI have a relatively high PA of 9.48 and $9.33 \mathrm{eV}$, respectively. NIMO which has the highest PA of $9.54 \mathrm{eV}$ of all studied compounds did not form a dimer (Fig. 3e), which may suggest that the clustering takes place through the imidazole ring. However, the PA of ORNI $(9.39 \mathrm{eV})$ is also comparable to that of METRO and RONI but again an ORNI dimer formation is 
not observed (Fig. 3d), which shows that high PA is not prerequisite for the formation of a dimer.

The spectra shown in Fig. 3 are obtained by summing up several hundred scans. All the compounds were sprayed with the same ESI source settings, thus, it is interesting to compare the intensity of $[\mathrm{M}+\mathrm{H}]^{+}$in counts per scan for the different radiosensitizers in relation to the PA of $\mathbf{M}$ (see Fig. 3f). In mass spectrometry, it is usually assumed that the measured ion intensity has a linear dependence on the amount of material in the sample, however, for an accurate quantitation a further analysis would be required, such as, the use of external or internal standard methods. ${ }^{29}$ According to DFT calculations NIMO has the highest PA value and as can be seen in Fig. $3 \mathrm{f}$ also the $[\mathrm{M}+\mathrm{H}]^{+}$ signal of NIMO is found experimentally to have the largest value of the five radiosensitizers under considerations. The trend in Fig. $3 \mathrm{f}$ is as expected, the higher the PA, the higher the
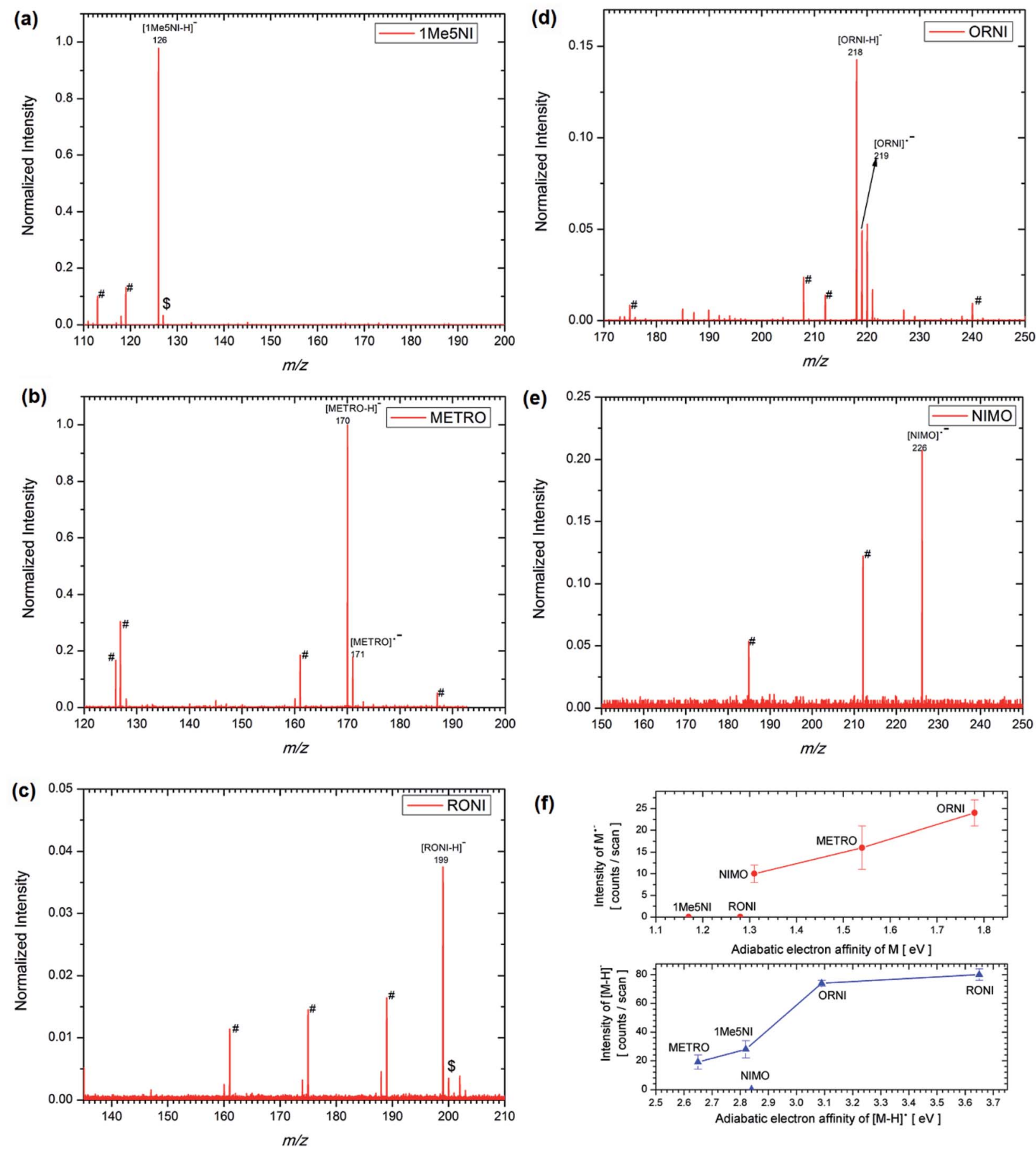

(f)
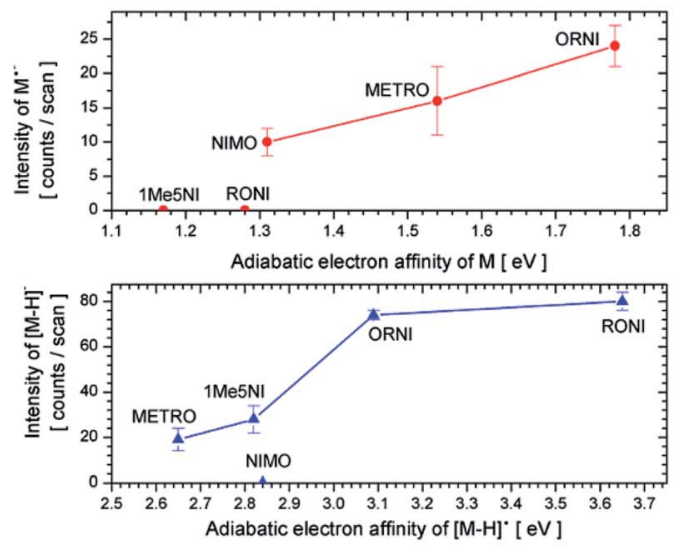

Fig. 4 Negative electrospray ionization mass spectra of a solution of $5 \mathrm{mM}$ of (a) 1Me5NI (b) METRO (c) RONI (d) ORNI (e) NIMO in methanol/ water (50/50). (f) Ion intensity of $\mathrm{M}^{\cdot-}$ and $[\mathrm{M}-\mathrm{H}]^{-}$in counts per scan plotted as a function of AEA of $\mathrm{M}$ and $[\mathrm{M}-\mathrm{H}]^{\circ}$, respectively. Background peaks are designated by \# and isotope peaks by $\$$. 
abundance of the $[\mathrm{M}+\mathrm{H}]^{+}$. Nevertheless, RONI and especially METRO diverge from this trend by rather low abundances observed. Accounting for the dimer formation in the case of RONI and METRO (Fig. 3f), the intensity of the ion formation through protonation reactions does not change significantly. One possible explanation for the observed discrepancy for METRO and RONI could be a preference for the protonation at another site than N3 in the solution. As can be seen from Fig. 3c, RONI shows also relatively high affinity towards sodium cation forming $[\mathrm{RONI}+\mathrm{Na}]^{+}$and $\left[\mathrm{RONI}_{2}+\mathrm{Na}\right]^{+}$, which compete with the formation of protonated species. On the other hand, we note that RONI and METRO are two compounds that are required to be stored at low temperatures of $-20{ }^{\circ} \mathrm{C}$ and $2-8{ }^{\circ} \mathrm{C}$, respectively, thus, some thermal decomposition is also likely and could influence the spraying outcome in the ESI source. In the Fig. $3 \mathrm{~b}$ and $\mathrm{c}$ no decomposition products are observed below the mass of $[\mathrm{M}+\mathrm{H}]^{+}$down to the $m / z 80$, which is the low mass cutoff of the mass spectrometer, however, we have no information on any possible decomposition products with lower $m / z$ than 80 .

\section{Formation of the radical anion $\mathrm{M}^{--}$versus the deprotonated anion $[\mathbf{M}-\mathbf{H}]^{-}$}

An examination of the negative ion ESI mass spectra of the radiosensitizers $1 \mathrm{Me} 5 \mathrm{NI}$, METRO, RONI and ORNI shown in Fig. 4a-d, respectively, shows the formation of their deprotonated anion $[\mathrm{M}-\mathrm{H}]^{-}$to be the most abundant ion in the spectra. On the other hand, in the case of NIMO (Fig. 4e), the radical anion $\mathbf{M}^{\cdot-}$ is the most abundant anion in the ESI spectrum, and the radical anion of METRO and ORNI is the second most abundant ion; in case of 1Me5NI no radical anion $\mathbf{M}^{\cdot-}$ can be observed. This is in contrast to a previous study, ${ }^{22}$ where $1 \mathrm{Me} 5 \mathrm{NI}$ in methanol solution lead to the formation of radical anions in nearly twice the abundance of the deprotonated anion. Also different to the previous study, ${ }^{22}$ here NIMO does not produce a deprotonated anion. This difference in the abundance of $\mathbf{M}^{--}$versus deprotonated anion $[\mathrm{M}-\mathrm{H}]^{-}$could be due to the differing ESI source design used in these two studies.

The structures of the radical anions $\mathrm{M}^{\cdot-}$ of $1 \mathrm{Me} 5 \mathrm{NI}, \mathrm{METRO}$, RONI, ORNI, and NIMO, were investigated by M062x/6$311+\mathrm{G}(\mathrm{d}, \mathrm{p})$ level of theory and the calculated minimum energy structures and their respective singly occupied molecular orbitals (SOMOs) visualized using Avogadro are shown in Fig. 5. The figure also includes the calculated AEAs of the compounds studied.

For the $1 \mathrm{Me} 5 \mathrm{NI}$ only one stable conformer is found with an AEA of $1.17 \mathrm{eV}$. In the case of METRO five different conformers were found within $0.1 \mathrm{eV}$, and the highest AEA of $1.54 \mathrm{eV}$ is not found for the lowest neutral conformer but for a conformer of $\sim 50 \mathrm{meV}$ higher in energy (see Fig. S2 in ESI $\dagger$ ). For RONI also five conformers were found within $0.15 \mathrm{eV}$, with the AEA of $1.28 \mathrm{eV}$ derived for the most stable neutral conformer (Fig. S3 in ESI $\dagger$ ). For ORNI we have identified six conformers within $0.14 \mathrm{eV}$ with an AEA of $1.78 \mathrm{eV}$. Notably, the possible interaction of the $-\mathrm{OH}$ group in the side chain on the $\mathrm{N} 1$ position with the $-\mathrm{NO}_{2}$ group in METRO and ORNI leads apparently to a stabilization of the radical anion, as indicated also by the high AEA of
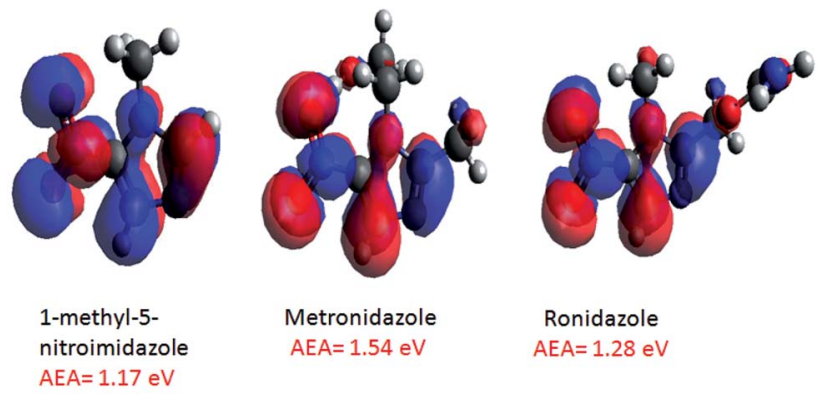

$$
\mathrm{AEA}=1.17 \mathrm{eV}
$$

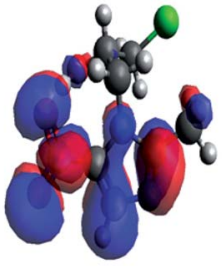

Ornidazole $\mathrm{AEA}=1.78 \mathrm{eV}$

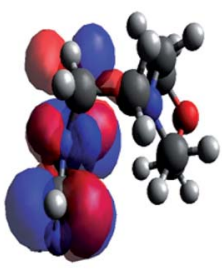

Nimorazole $\mathrm{AEA}=1.31 \mathrm{eV}$

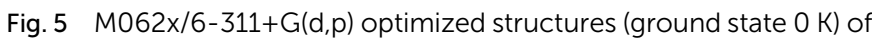
radical anions of $1 \mathrm{Me} 5 \mathrm{NI}, \mathrm{METRO}, \mathrm{RONI}, \mathrm{ORNI}$, and NIMO, and their SOMOs, and calculated AEAs.

1.54 and $1.78 \mathrm{eV}$, respectively. The relative order of the AEAs of the compounds studied is $1 \mathrm{Me} 5 \mathrm{NI}<\mathrm{RONI}<\mathrm{NIMO}<\mathrm{METRO}<$ ORNI. Interestingly, we observe radical anion formation only for NIMO, METRO and ORNI only, see Fig. 4.

Fig. 5 also shows the SOMOs of the studied radiosensitizers, 1Me5N1, METRO, RONI, ORNI, and NIMO. As can be seen, the extra electron in the anionic system is delocalized over the whole nitroimidazole ring. It is obvious that this is not effected by adding a different side chain onto the $\mathrm{N} 1$ position of the nitroimidazole ring and neither the molecular change at position $\mathrm{C} 2$. Because the extra electron is delocalized over the whole nitroimidazole ring in all compounds studied and not localized on a specific part of the molecule as in dipole bound states, it is expected that the vertical detachment energy (VDE) will differ from the AEA. Indeed, the VDEs were calculated to be substantially higher than the respective AEA (Table 2). The highest difference is in case of ORNI, where VDE is $2.50 \mathrm{eV}$, while the AEA is $1.78 \mathrm{eV}$. Additionally, the rather large positive values of all AEAs, VDEs, and VEAs calculated (see Table 2) is responsible that the 5-nitroimidazolic compounds under investigation here should be able to form very stable radical anions and indeed for NIMO, METRO and ORNI the radical anions are observed in the ESI-TOF mass spectra.

In the formation of deprotonated $[\mathrm{M}-\mathrm{H}]^{-}$ions of the five radiosensitizers, two processes were considered. In the first, the loss of $\mathrm{H}^{+}$from a neutral molecule $\mathrm{M}$ (eqn (1)), and in the second, the loss of $\mathrm{H}^{\cdot}$ from a radical anion $\mathrm{M}^{*-}$ (eqn (2)).

$$
\begin{aligned}
& \mathrm{M} \rightarrow[\mathrm{M}-\mathrm{H}]^{-}+\mathrm{H}^{+} \\
& \mathbf{M}^{\cdot-} \rightarrow[\mathrm{M}-\mathrm{H}]^{-}+\mathrm{H}^{\cdot}
\end{aligned}
$$

For the formation of the $[\mathrm{M}-\mathrm{H}]^{-}$ion, the radical $[\mathrm{M}-\mathrm{H}]^{\cdot}$ must have a positive AEA, thus, we have also calculated the AEA 
Table 2 Summary of calculated proton affinities (PAs), adiabatic electron affinities (AEAs), vertical electron affinities (VEAs) and vertical detachment energies (VDEs) and the formation of deprotonated ion $[\mathrm{M}-\mathrm{H}]^{-}$via eqn (1) and (2)

\begin{tabular}{|c|c|c|c|c|c|c|c|}
\hline Compound & $\begin{array}{l}\mathrm{PA}(\mathrm{eV}) \\
{[\mathrm{M}+\mathrm{H}]^{+}}\end{array}$ & $\begin{array}{l}\text { AEA (eV) } \\
\mathbf{M}^{--}\end{array}$ & $\begin{array}{l}\text { VEA }(\mathrm{eV}) \\
\mathbf{M}^{--}\end{array}$ & $\begin{array}{l}\operatorname{VDE}(\mathrm{eV}) \\
\mathbf{M}^{\bullet^{-}}\end{array}$ & (1) $(\mathrm{eV})[\mathrm{M}-\mathrm{H}]^{-}$ & (2) $(\mathrm{eV})[\mathrm{M}-\mathrm{H}]^{-}$ & $\begin{array}{l}\text { AEA (eV) } \\
{[\mathrm{M}-\mathrm{H}]^{\circ}}\end{array}$ \\
\hline 1-Methyl-5-nitroimidazole & $9.06\left(\mathrm{~N}_{3}-\mathrm{H}\right)$ & 1.17 & 0.78 & 1.51 & $15.72\left(\mathrm{C}_{2}-\mathrm{H}\right)$ & $3.34\left(\mathrm{C}_{2}-\mathrm{H}\right)$ & 2.82 \\
\hline Metronidazole & $9.48\left(\mathrm{~N}_{3}-\mathrm{H}\right)$ & 1.54 & 0.94 & 2.03 & $15.37(\mathrm{O}-\mathrm{H})$ & $3.10(\mathrm{O}-\mathrm{H})$ & 2.65 \\
\hline Ronidazole & $9.33\left(\mathrm{~N}_{3}-\mathrm{H}\right)$ & 1.28 & 0.74 & 1.73 & $14.84(\mathrm{~N}-\mathrm{H})$ & $2.57(\mathrm{~N}-\mathrm{H})$ & 3.65 \\
\hline Ornidazole & $9.39\left(\mathrm{~N}_{3}-\mathrm{H}\right)$ & 1.78 & 1.14 & 2.50 & $15.11(\mathrm{O}-\mathrm{H})$ & $2.91(\mathrm{O}-\mathrm{H})$ & 3.09 \\
\hline Nimorazole & $9.54\left(\mathrm{~N}_{1}{ }^{1}-\mathrm{H}\right)$ & 1.31 & 0.82 & 1.73 & $15.68\left(\mathrm{C}_{2}-\mathrm{H}\right)$ & $3.44\left(\mathrm{C}_{2}-\mathrm{H}\right)$ & 2.84 \\
\hline
\end{tabular}
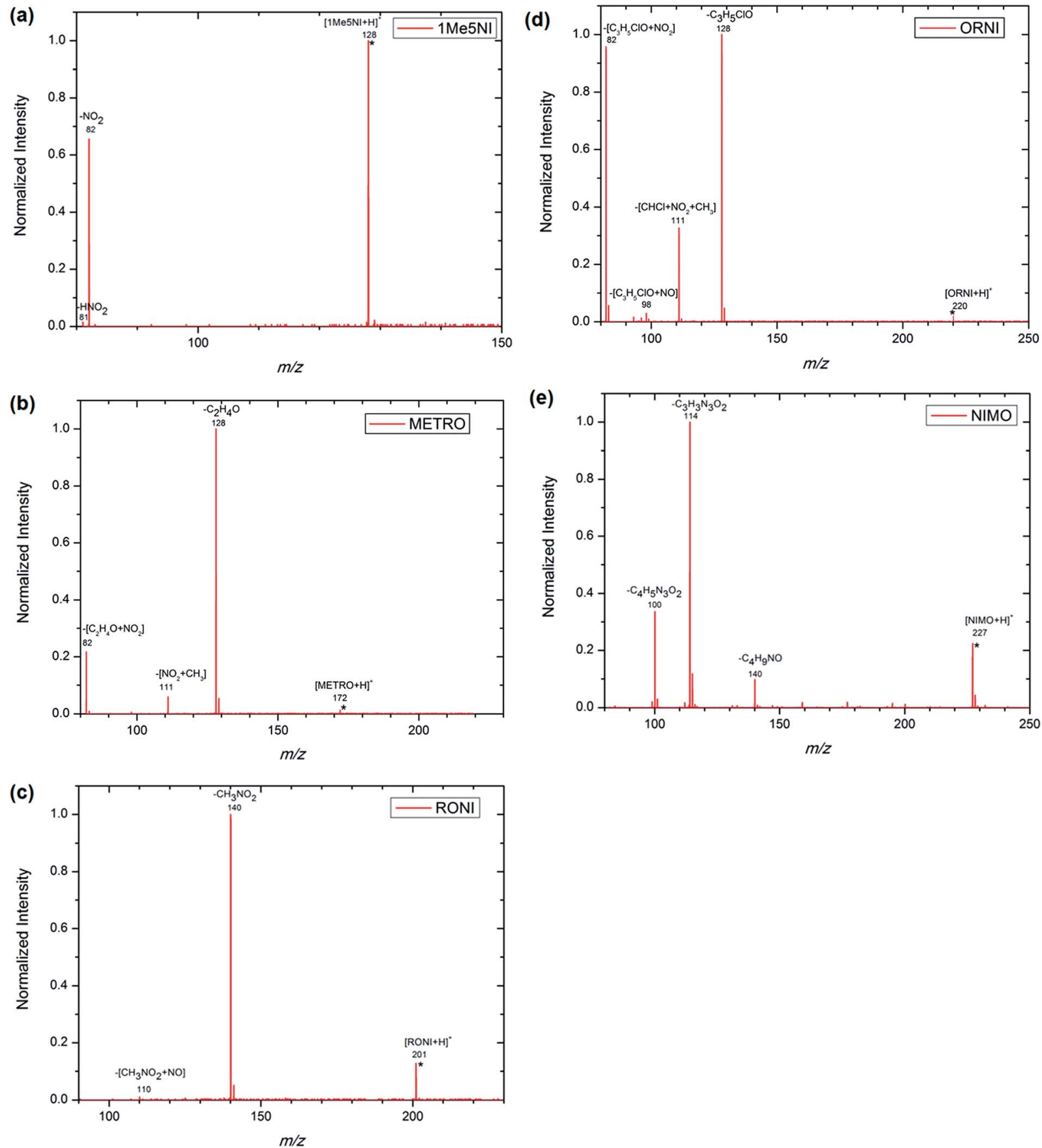

Fig. 6 Fragmentation spectra of positive ions $\left[M+\mathrm{H}^{+}\right.$, (a) $1 \mathrm{Me} 5 \mathrm{NI}$ (b) METRO (c) RONI (d) ORNI (e) NIMO. These CID spectra of $[M+\mathrm{H}]^{+}$ reported here were recorded at a collision voltage of $15 \mathrm{~V}$. The mass selected precursor ion is designated by a *. 
of $[\mathrm{M}-\mathrm{H}]^{\circ}$. The results are given in Table 2 . From the Table 2 it can be seen that to form $[\mathrm{M}-\mathrm{H}]^{-}$ion via both, eqn (1) and (2), requires the least energy in case of RONI, then ORNI, METRO, NIMO and $1 \mathrm{Me} 5 \mathrm{NI}$, and only NIMO showed no formation of [M $-\mathrm{H}]^{-}$(see also Fig. 4e). However, from the Fig. 4 we see that both, formation of $\mathbf{M}^{\cdot-}$ and $[\mathbf{M}-\mathrm{H}]^{-}$are in competition. Additionally, as already mentioned above, in another ESI-MS study $^{22}$ the deprotonated NIMO was observed. Thus, there are two discrepancies in comparison to this previous study, ${ }^{22}$ here, we do not observe deprotonated NIMO nor the radical anion of 1Me5NI. From the technical point of view, we can only point out the difference in the ESI source design, where in the current study we utilize Z-spray ESI source built by Waters in comparison to ESI source from Finnigan in the previous study.
Fig. 4f shows the ion intensity of $\mathrm{M}^{--}$and $[\mathrm{M}-\mathrm{H}]^{-}$in counts per scan plotted as a function of AEA of $M$ and $[M-H]^{\cdot}$, respectively. The intensity of the $\mathbf{M}^{\cdot-}$ tracks well with the increasing AEA of $\mathrm{M}$, while 1Me5NI and RONI have not formed at all a radical anion $\mathbf{M}^{\cdot-}$. Even though RONI has relatively high AEA, it has also the smallest energy requirements for the formation of $[\mathrm{M}-\mathrm{H}]^{-}$via eqn (1) and (2), and thus likely favors the formation of deprotonated ion as opposed to radical anion formation (Fig. 4c). The intensity of the $[\mathrm{M}-\mathrm{H}]^{-}$in Fig. $4 \mathrm{f}$ is also increasing with the AEA of $[\mathrm{M}-\mathrm{H}]^{\circ}$ as expected, while however no $[\mathrm{M}-\mathrm{H}]^{-}$anion was observed in case of NIMO. The AEA of $[\mathrm{M}-\mathrm{H}]^{\cdot}$ for NIMO is relatively high, nevertheless, the formation of the radical anion $\mathrm{M}^{--}$is preferred.

(a)

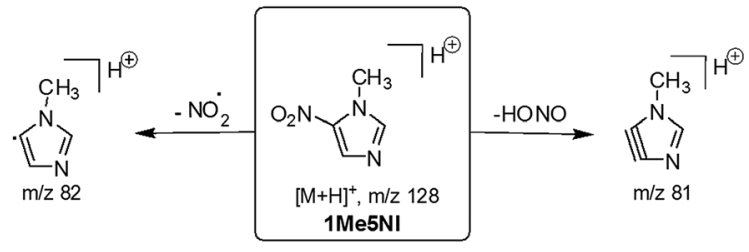

(b)

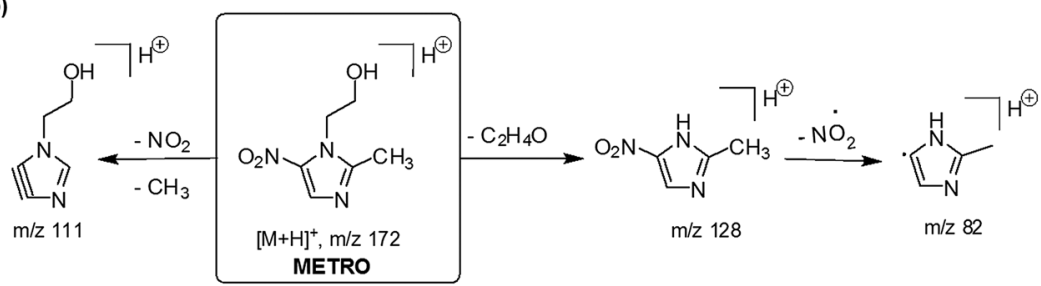

(c)

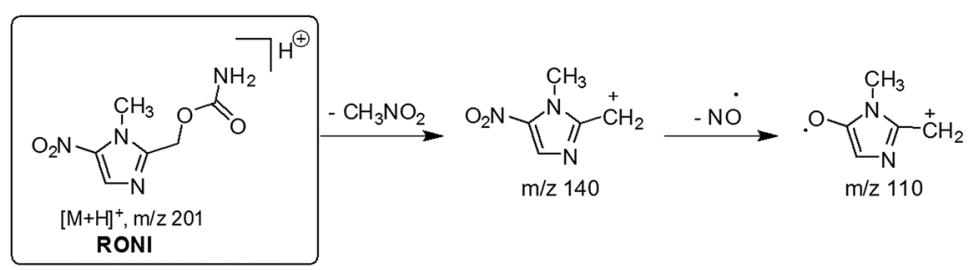

(d)

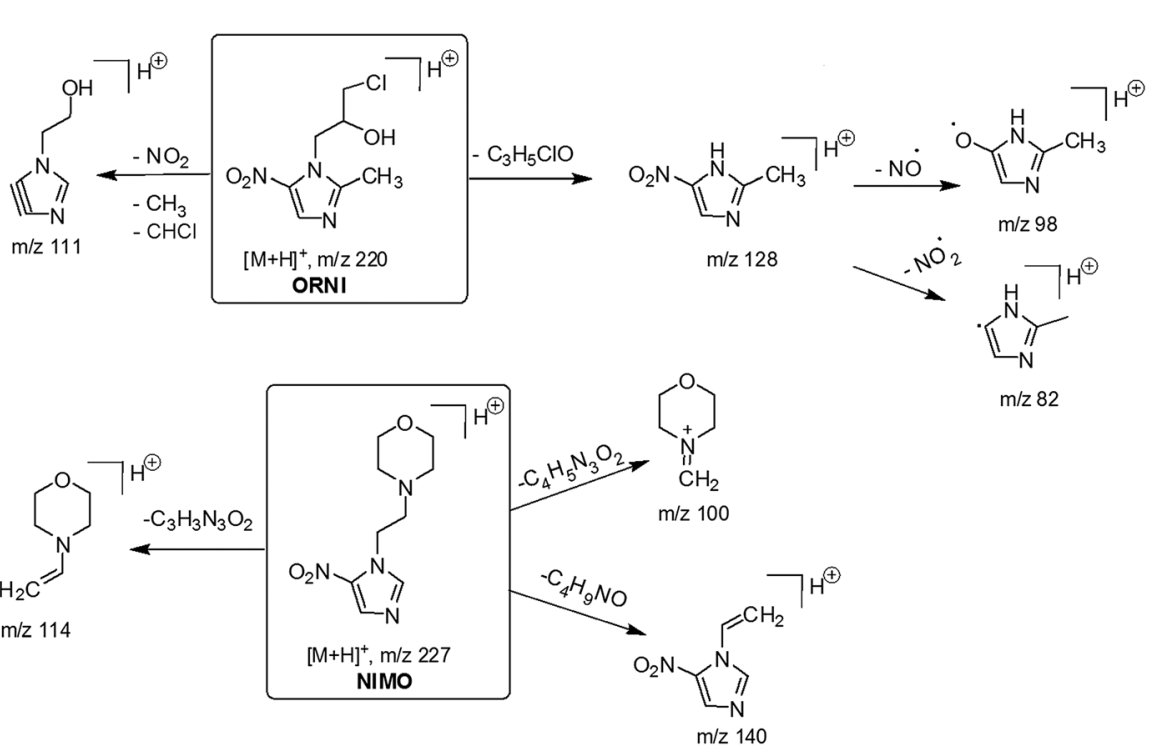

(e)

Fig. 7 Proposed fragmentation pathways for $\left[\mathrm{M}+\mathrm{H}^{+}\right.$ions of (a) $1 \mathrm{Me} 5 \mathrm{NI}$ (b) METRO (c) RONI (d) ORNI and (e) NIMO. 


\section{Collision-induced dissociation of $[\mathbf{M}+\mathbf{H}]^{+}$}

In order to elucidate the major fragmentation pathways for the protonated $[\mathrm{M}+\mathrm{H}]^{+}$ions of radiosensitizers, we have performed low-energy CID of these $[\mathrm{M}+\mathrm{H}]^{+}$ions. The CID mass spectra of $[\mathrm{M}+\mathrm{H}]^{+}$ions of $1 \mathrm{Me} 5 \mathrm{NI}$, METRO, RONI, ORNI and NIMO are shown in Fig. 6. Potential structures of the fragment ions are depicted in Fig. 7. The CID of $1 \mathrm{Me} 5 \mathrm{NI}$ leads to the losses of $\mathrm{NO}_{2}{ }^{\text {. }}$ and HONO to form fragment ions at $\mathrm{m} / \mathrm{z} 82$ and $\mathrm{m} / \mathrm{z} 81$ respectively. The CID spectrum of the protonated METRO in Fig. $6 \mathrm{~b}$ exhibits as the most abundant fragment ion a signal at $m / z 128$, however, in this case the ion corresponds to a protonated nitroimidazole ring, i.e., the loss took place from $\mathrm{N} 1$ position (Fig. 7). The losses of $\mathrm{NO}_{2}{ }^{\circ}$ and $\mathrm{CH}_{3}$ lead to fragment ions at $m / z 82$ and 111 , respectively.

The CID spectrum of the protonated RONI (Fig. 6c) shows the loss of the side chain from the nitroimidazole ring to form an ion with $m / z 140$. Further loss of NO from the ion at $m / z 140$ resulted in the fragment ion at $m / z 110$ (Fig. 7).

The CID spectrum of the protonated ORNI (Fig. 6d) gives rise to the same fragment ions as in the case of METRO, i.e., through the loss of $\mathrm{NO}_{2}{ }^{\circ}$ forming a fragment ion at $\mathrm{m} / \mathrm{z}$ 82, and via the loss of $\left[\mathrm{CH}_{3}+\mathrm{NO}_{2}+\mathrm{CHCl}\right]$ forming a fragment ion at $m / z 111$. Additionally, the fragment ion at $\mathrm{m} / \mathrm{z} 98$ in the CID spectrum likely corresponds to additional loss of the NO from the $\mathrm{m} / z 128$ (Fig. 7).

The CID of protonated NIMO (Fig. 6e) gives rise to two most abundant fragment ions at $\mathrm{m} / z 114$ and $\mathrm{m} / \mathrm{z} 100$ and both of these correspond to the loss of the side chain from the nitroimidazole ring, with charge retention by the side chain, which is consistent with the highest calculated PA of the side chain in NIMO (see Fig. 2). On the other hand, when the charge is retained by the nitroimidazole ring, a fragment ion at $m / z 140$ is formed (Fig. 7). Our results are in agreement in terms of relative abundances of fragment ions formed with the previous study on fragmentation reactions of NIMO by a different activation methods, ${ }^{22}$ where the fragment ion at $\mathrm{m} / \mathrm{z} 114$ is the most abundant, followed by a lower intensity of ions at $\mathrm{m} / \mathrm{z} 100$ and 140.

The losses of $\mathrm{NO}^{\cdot}$ and $\mathrm{NO}_{2}{ }^{\cdot}$ are due to the nitro functional group. These losses are characteristic for nitroimidazoles irrespective of the nature of the charge of the formed precursor ion. ${ }^{28}$ From the Fig. 7 , one can see that $1 \mathrm{Me} 5 \mathrm{NI}$ dissociates only by loss of $\mathrm{NO}_{2}{ }^{\circ}$ and $\mathrm{HONO}$, while for the other radiosensitizers, the side chain at the $\mathrm{N} 1$ cleaves first, followed by the loss of NO${ }^{*}$ or $\mathrm{NO}_{2}{ }^{\cdot}$ radicals. Cleavage of the $\mathrm{CH}_{3}$ from the $\mathrm{C} 2$ position is observed for both, METRO and ORNI, with the $\mathrm{CH}_{3}$ group on $\mathrm{C} 2$. NIMO is the radiosensitizer with the most different behavior from all in which case the high PA of the side chain at N1 governs the fragmentation pathway. Thus, the formation of an ion at $\mathrm{m} / \mathrm{z} 140$ has not enough internal energy to further fragment (by loss of $\mathrm{NO}^{*}, \mathrm{NO}_{2}{ }^{*}$ or other molecules). In summary, three of the studied compounds dissociate via $\mathrm{NO}_{2}{ }^{\cdot}$ loss, 1Me5NI, METRO, ORNI (Fig. 5a, b and d), while NO ${ }^{\circ}$ loss is shown only for RONI and ORNI (Fig. 5c, d, and 7) and neither of these losses were observed for NIMO (Fig. 5e). Note, that the loss of $\mathrm{NO}_{2} \cdot$ requires simple $\mathrm{C}-\mathrm{N}$ bond cleavage while the loss of
$\mathrm{NO}^{*}$ involves a transition state (TS) involving nitro-nitrite isomerization that leads then to an immediate loss of $\mathrm{NO}^{*} .^{30}$ The TS for the loss of $\mathrm{NO}^{\circ}$ proves to be always below the bond dissociation energy to release $\mathrm{NO}_{2}{ }^{\circ}$ for these simple nitroimidazoles. ${ }^{30}$ The only compound that did not show a loss of $\mathrm{NO}^{\circ}$ or $\mathrm{NO}_{2}{ }^{\circ}$ in the presently measured low-energy CID is NIMO, nevertheless small abundance for these loss channels were noted previously. ${ }^{22}$ Our results suggest that investigated nitroimidazolic compounds are first prone to dissociation at the N1 position unless the group is $\mathrm{CH}_{3}$, followed by typical losses of $\mathrm{NO}^{\bullet}$ or $\mathrm{NO}_{2}{ }^{\cdot}$ radicals. The loss of HONO in $1 \mathrm{Me} 5 \mathrm{NI}$ has been observed also for simple nitroimidazoles but only in electroninduced dissociation, ${ }^{30}$ however, here it is a minor channel.

\section{Conclusions}

The present study have investigated positive and negative ion formation of radiosensitizers 1Me5NI, METRO, RONI, ORNI and NIMO using ESI mass spectrometry and quantum chemical calculations.

In the positive ion mode of the ESI, the most abundant ion in the spectra was the protonated radiosensitizer $[\mathrm{M}+\mathrm{H}]^{+}$ion. The highest PA for all radiosensitizers is on the $\mathrm{N} 3$ of the imidazole ring ( $9.06 \mathrm{eV}$ to $9.48 \mathrm{eV}$ ), but for NIMO, the highest PA is found at the nitrogen site of the morpholine ring $(9.54 \mathrm{eV})$. The calculated PAs of the radiosensitizers are in relative order 1 Me5NI < RONI < ORNI < METRO < NIMO. Radiosensitizers METRO and RONI exhibit formation of protonated dimers $\left[\mathrm{M}_{2}+\right.$ $\mathrm{H}]^{+}$, in addition RONI exhibits also sodiated dimer $\left[\mathrm{M}_{2}+\mathrm{Na}\right]^{+}$ with a rather large abundance.

In the negative ion mode of the ESI, all radiosensitizers except NIMO show the formation of deprotonated anion [M $\mathrm{H}]^{-}$, whereas the formation of the radical anion $\mathbf{M}^{\bullet^{-}}$was observed only for NIMO, METRO and ORNI. The DFT calculations suggested that radical anion formation $\mathbf{M}^{\cdot-}$ should be possible due to the high positive values of AEAs, VDEs and VEAs of all the radiosensitizers. NIMO, METRO and ORNI have the highest AEAs of 1.31, 1.54 and $1.78 \mathrm{eV}$, respectively. The relative order of the AEAs of all radiosensitizers investigated is $1 \mathrm{Me} 5 \mathrm{NI}$ $<$ RONI < NIMO < METRO < ORNI. Quantum chemical calculations on the radical anion $\mathbf{M}^{--}$revealed that the possible interaction of an - $\mathrm{OH}$ group in the side chain on $\mathrm{N} 1$ position with the $-\mathrm{NO}_{2}$ group, as in case of METRO and ORNI, leads to stabilization of the radical anion. The extra electron in the anionic system of $\mathbf{M}^{\cdot-}$ is delocalized over the whole nitroimidazole ring, and this is not affected by adding a different side chain onto position N1 neither C2 of the nitroimidazole ring. In the case of even electron deprotonated ions only NIMO showed no formation of $[\mathrm{M}-\mathrm{H}]^{-}$. Two processes were considered in the formation of $[\mathrm{M}-\mathrm{H}]^{-}$by quantum chemical calculations, the loss of $\mathrm{H}^{+}$from a neutral molecule, and the loss of $\mathrm{H}^{\cdot}$ from radical anion $\mathrm{M}^{\cdot-}$. For both processes, the order of increasing energy necessary to form $[\mathrm{M}-\mathrm{H}]^{-}$is RONI $<$ORNI $<$ METRO $<$ NIMO < 1Me5NI. Considering the AEA of $[\mathrm{M}-\mathrm{H}]^{\circ}$, the intensity of $[\mathrm{M}-\mathrm{H}]^{-}$increases with the increasing AEA, except for NIMO that prefers the formation of $\mathrm{M}^{-}{ }^{-}$. ESI mass spectrometry results showed that the formation of $\mathbf{M}^{--}$and $[\mathrm{M}$ 
$-\mathrm{H}]^{-}$are both in competition. Differences in observations concerning an earlier study are ascribed to instrumental differences concerning the ESI source.

Low-energy CID of protonated radiosensitizers $[\mathrm{M}+\mathrm{H}]^{+}$ typically leads to the loss of $\mathrm{NO}_{2}{ }^{-}$for $1 \mathrm{Me} 5 \mathrm{NI}, \mathrm{METRO}, \mathrm{ORNI}$, and loss of $\mathrm{NO}^{\circ}$ for RONI and ORNI. The only compound that did not show these two decay channels is NIMO. The CID of [M $+\mathrm{H}]^{+}$suggests that nitroimidazolic compounds investigated here are first prone to dissociation at $\mathrm{N} 1$ position, unless the group at $\mathrm{N} 1$ is $-\mathrm{CH}_{3}$, followed by typical losses of $\mathrm{NO}^{\circ}$ or $\mathrm{NO}_{2}{ }^{\text {. }}$ radicals.

\section{Experimental}

\section{Materials}

1Me5NI (1), METRO (2), RONI (3) and ORNI (4) (see Fig. 1) were purchased from Sigma Aldrich (98\%) and NIMO (5) was a gift of Prof. Michael Horsman of Aarhus University Hospital. All compounds were used as received.

\section{Mass spectrometry}

All experiments were carried out using a commercially available instrument (Ultima, Waters-Micromass, UK), where a Z-spray electrospray ionization (ESI) source is combined with a timeof-flight mass spectrometer (ESI-TOF MS). $5 \mathrm{mM}$ solution of each radiosensitizer (1Me5NI, METRO, RONI, ORNI and NIMO) was dissolved in methanol/water/acetic acid (50/50/1) and continuously sprayed at 4.5 bar of the nitrogen drying gas into a differentially pumped region at a working pressure of 1.6 mbar. The constant injection rate of $15\left(\mu \mathrm{L} \min ^{-1}\right)$ was controlled by means of a syringe pump (NewEra Syringe pump Systems Inc.). In the positive mode the ESI needle was biased at $+2.98 \mathrm{kV}$ and a voltage of $+34 \mathrm{~V}$ was applied to the cone. In the negative mode the samples were dissolved in methanol/water (50/50), the ESI needle was biased at $-3.41 \mathrm{kV}$ and a voltage of $-54 \mathrm{~V}$ was applied to the cone. The source and desolvation temperatures were set to $363 \mathrm{~K}$ and $423 \mathrm{~K}$, respectively. For further ESI source and MS settings details please see Table S1 in ESI. $\dagger$ For the tandem mass spectrometry experiments, the desired ions produced via ESI were mass selected and subjected to CID in the collision region reaching a pressure of $5 \times 10^{-5}$ mbar. The collision voltage can be varied between 0 and $30 \mathrm{~V}$ and the CID spectra reported here were recorded at a collision voltage of $15 \mathrm{~V}$.

\section{Molecular modeling}

Geometries of 1ME5NI, METRO, RONI and ORNI were found through conformational search using Avogadro. For NIMO we used the lowest structure reported in Feketeová et. al. ${ }^{22} \mathrm{~A}$ selection of structures of very different conformations within $0.5 \mathrm{eV}$ were chosen and subsequently optimized at the M062x/ $6-311+G(d, p)$ level of theory and basis set with the Gaussian09B01 program package. ${ }^{31}$ Frequencies were calculated to confirm that the structures are local minima on the potential energy surface and not the transition states. For the lowest structures of the five radiosensitizers we have calculated the PAs for each possible protonation site, adiabatic electron affinities (AEAs), vertical electron affinities (VEAs), vertical detachment energies (VDEs), and deprotonation reactions. All energies were corrected for zero-point energies. All structures calculated including relative energies are given in the (ESI), Fig. S1-S5. $\dagger$

\section{Conflicts of interest}

There are no conflicts to declare.

\section{Acknowledgements}

S. P. is thankful to the Council of Scientific and Industrial Research (CSIR), New Delhi, CEFIPRA, New Delhi in form of Raman-Charpak for financial support. L. F. is thankful for the support from the Vicerectorate for Research - University of Innsbruck via P7440-035-011, and the Institut de Physique Nucleáire de Lyon. The crucial computing support from CCIN2P3 (France) is acknowledged gratefully. The authors gratefully acknowledge Ian Walker, Waters Corporation, for his technical expertise.

\section{References}

1 L. Shi, R. Hu, Y. Wei, Y. Liang, Z. Yang and S. Ke, Anthranilic acid-based diamides derivatives incorporating arylisoxazoline pharmacophore as potential anticancer agents: design, synthesis and biological evaluation, Eur. J. Med. Chem., 2012, 54, 549-556.

2 G. Delaney, S. Jacob, C. Featherstone and M. Barton, The role of radiotherapy in cancer treatment, Cancer, 2005, 104, 1129.

3 C. Von Sonntag, The Chemical Basis of Radiation Biology, Taylor and Francis, London, 1987.

4 C. Von Sonntag, Physical and Chemical Mechanisms in Molecular Radiation Biology, Plenum Press, New York, 1991.

5 E. Alizadeh and L. Sanche, Measurements of $G$-values for DNA Damage Induced by Low Energy Electrons, Nature, 2009, 461, 358-359.

6 J. E. Moulder and S. Rockwell, Tumor hypoxia: its impact on cancer therapy, Cancer Metastasis Rev., 1987, 5, 313-341.

7 L. Sanche, M. K. Shukla and J. Leszczynsky, Radiation Induced Molecular Phenomena in Nucleic Acids, 2008, vol. 131, pp. 531-575.

$8 \mathrm{P}$. Wardman, Chemical radiosensitizers for use in radiotherapy, Clin. Oncol., 2007, 19, 397-417.

9 J. Overgaard, H. S. Hansen, M. Overgaard, L. Bastholt, A. Berthelsen, L. Specht, B. Lindeløv and K. Jørgensen, A randomized double-blind phase III study of nimorazole as a hypoxic radiosensitizer of primary radiotherapy in supraglottic larynxand pharynx carcinoma. Results of the Danish Head and Neck Cancer Study (DAHANCA) Protocol 5-85, Radiother. Oncol., 1998, 46, 135-146.

10 P. Cornago, L. Santos, Y. Smeyers, C. Lopez Zumel and C. Izqierdo, Chem.-Biol. Interact., 1992, 82, 47-53.

11 S. Roffia, C. Gottardi and E. Vianello, Autoprotonation of anion radical and redox-catalysed reduction of the 
supporting electrolyte cation, J. Electroanal. Chem., 1982, 142, 263-275.

12 G. J. Van Berkel, S. A. McLuckey and G. L. Glish, Electrochemical origin of radicalcations observed in electrospray ionization mass spectra, Anal. Chem., 1992, 64, 1586-1593.

13 T. Guaratini, R. L. Vessecchi, F. C. Lavarda, P. M. B. G. Maia Campos, Z. Naal, P. J. Gates and N. P. Lopes, New chemical evidence for the ability to generate radical molecular ions of polyenes from ESI and HR-MALDI mass spectrometry, Analyst, 2004, 129, 1223-1226.

14 M. Schäfer, M. Drayß, A. Springer, P. Zacharias and K. Meerholz, Radical cations inelectrospray mass spectrometry: Formation of open-shell species, examination of the fragmentation behavior in ESI-MS and reaction mechanism studies by detection of transient radical cations, Eur. J. Org. Chem., 2007, 207, 5162-5174.

15 T. Guaratini, P. J. Gates, E. Pinto, P. Colepicolo and N. P. Lopes, Differential ionization of natural antioxidant polyenes in electrospray and nanospray mass spectrometry, Rapid Commun. Mass Spectrom., 2007, 21, 3842-3848.

16 E. M. Thurman, I. Ferrer, O. J. Pozo, J. V. Sancho and F. Hernandez, The even-electronrule in electrospray mass spectra of pesticides, Rapid Commun. Mass Spectrom., 2007, 21, 3855-3868.

17 K. Hiraoka, I. Kudaka, S. Fujimaki and H. Shinohara, Observation of the fullerene anions $\mathrm{C} 60$ and $\mathrm{C70}$ by electrospray ionization, Rapid Commun. Mass Spectrom., 1992, 6, 254-256.

18 G. N. Khairallah and J. B. Peel, Identification of dianions of C84 and C90 by electrospray mass spectrometry, Chem. Phys. Lett., 1998, 296, 545-548.

19 S. Fujimaki, I. Kudaka, T. Sato, K. Hiraoka, H. Shinohara, Y. Saito and K. Nojima, Application of electrospray ionization to the observation of higher fullerene anions, Rapid Commun. Mass Spectrom., 1993, 7, 1077-1081.

20 D. M. Thompson, J. H. Brownie and M. C. Baird, Spectroscopic evidence for anionic coordination complexes of the transition metals with $\mathrm{C} 70$ and the higher fullerenes C76, C78, C82, C84, C86, C90, and C92, Fullerenes, Nanotubes, Carbon Nanostruct., 2004, 12, 697-713.

21 G. J. Van Berkel and V. Kertesz, Using the electrochemistry of the electrospray ion source, Anal. Chem., 2007, 79, 55105520.

22 L. Feketeová, A. Albright, B. S. Sørensen, M. R. Horsman, J. White, R. A. J. O'Hair and N. Bassler, Formation of radical anions of radiosensitizers and related model compounds via electrospray ionization, Int. J. Mass Spectrom., 2014, 365, 56-63.

23 J. Overgaard, H. S. Hansen, M. Overgaard, L. Bastholt, A. Berthelsen, L. Specht, B. Lindeløv and K. Jørgensen, A randomized double-blind phase III study of nimorazole as a hypoxic radiosensitizer of primary radiotherapy in supraglottic larynxand pharynx carcinoma. Results of the Danish Head and Neck Cancer Study (DAHANCA) Protocol 5-85, Radiother. Oncol., 1998, 46, 135-146.

$24 \mathrm{~J}$. Overgaard, Hypoxic modification of radiotherapy in squamous cell carcinoma of the head and neck a systematic review and meta-analysis, Radiother. Oncol., 2011, 100, 22-32.

25 P. Kumar, A. Rúbies, F. Centrich and R. Companyo, A false positive case due to matrix interference in the analysis of ronidazole residues in muscle tissue using LC-MS/MS, Meat Sci., 2014, 97, 214-219.

26 J. Du, P. Deng, X. Chen, H. Wang, T. You and D. Zhong, Characterization of ornidazole metabolites in human bile after intraveneous doses by ultra performance liquid chromatography/quadrupole time-of-flight mass spectrometry, Acta Pharm. Sin. B, 2012, 2, 159-167.

27 C. Desfrançois, H. Abdoul-Carime and N. Khelifa, From 1/r to $1 / \mathrm{r}^{2}$ potentials: Electron exchange between Rydberg atoms and polar molecules, Phys. Rev. Lett., 1994, 73, 2436-2439.

28 A. M. Scheer, K. Aflatooni, G. A. Gallup and P. D. Burrow, Bond breaking and temporary anion states in uracil and halouracils: Implications for the DNA bases, Phys. Rev. Lett., 2004, 92, 068102.

29 E. de Hoffmann and V. Stroobant, Mass Spectrometry, John Wiley \& Sons Ltd, Chichester, 2009.

30 L. Feketeová, J. Postler, A. Zavras, P. Scheier, S. Denifl and R. A. J. O'Hair, Decomposition of nitroimidazole ions: experiment and theory, Phys. Chem. Chem. Phys., 2015, 17, 12598-12607.

31 M. J. Frisch, G. W. Trucks, H. B. Schlegel, G. E. Scuseria, M. A. Robb, J. R. Cheeseman, G. Scalmani, V. Barone, B. Mennucci, G. A. Petersson, H. Nakatsuji, M. Caricato, X. Li, H. P. Hratchian, A. F. Izmaylov, J. Bloino, G. Zheng, J. L. Sonnenberg, M. Hada, M. Ehara, K. Toyota, R. Fukuda, J. Hasegawa, M. Ishida, T. Nakajima, Y. Honda, O. Kitao, H. Nakai, T. Vreven, J. A. Montgomery Jr, J. E. Peralta, F. Ogliaro, M. Bearpark, J. J. Heyd, E. Brothers, K. N. Kudin, V. N. Staroverov, T. Keith, R. Kobayashi, J. Normand, K. Raghavachari, A. Rendell, J. C. Burant, S. S. Iyengar, J. Tomasi, M. Cossi, N. Rega, J. M. Millam, M. Klene, J. E. Knox, J. B. Cross, V. Bakken, C. Adamo, J. Jaramillo, R. Gomperts, R. E. Stratmann, O. Yazyev, A. J. Austin, R. Cammi, C. Pomelli, J. W. Ochterski, R. L. Martin, K. Morokuma, V. G. Zakrzewski, G. A. Voth, P. Salvador, J. J. Dannenberg, S. Dapprich, A. D. Daniels, O. Farkas, J. B. Foresman, J. V. Ortiz, J. Cioslowski and D. J. Fox, Gaussian 09, Revision B.01, Gaussian, Inc., C. T, Wallingford, 2010. 